International Journal of Behavioral Research \& Psychology (IJBRP)

ISSN 2332-3000

\title{
Comparison of Personal Characteristic of Patients Affected By Broken Heart Syndrome and Acute Coronary Syndrome Vs. Healthy Subjects
}

Research Article

Esfahani $\mathrm{M} \mathrm{A}^{1^{*}}$, Baluchi $\mathrm{D}^{2}$, Behjati $\mathrm{M}^{3}$, Izadi $\mathrm{S}^{4}$

${ }^{1} \mathrm{MD}$, cardiologist, Associate professor of cardiology department of Isfahan University of medical sciences.

${ }^{2} \mathrm{MSc}$ of psychology, Khorasgan free university, Isfahan, Iran.

${ }^{3}$ MD, Cardiologist, Cardiovascular Research Center, Isfahan Cardiovascular Research Institute, Isfahan, Iran, Heart failure research center, Isfahan Cardiovascular Research Institute, Isfahan, Iran.

${ }^{4} \mathrm{MD}$, Heart failure research center, Isfahan Cardiovascular Research Institute, Isfahan, Iran.

\begin{abstract}
Background and purpose: There is a joint link between somatic disorders and psychological stresses. Since presence of underlying special psychological characters predispose persons to development of broken heart syndrome (BHS), we aimed to find out predisposing personal characteristics and their difference between cases with BHS, acute coronary syndromes and healthy subjects.

Methods and subjects: This case-control study was performed on 60 cases with diagnosed broken heart syndrome, 60 cases of acute coronary syndrome and 60 healthy subjects. All enrolled participants filed appropriate questionnaires after getting signed informed consent. Data were analyzed using SPSS ver.12 via MANOVA test.

Principal results: There was a significant difference in all three groups regarding psychosis $(\mathrm{P}<0.01)$, aggression and phobia $(\mathrm{P}<0.05)$. These characteristics were higher in cases with broken heart syndrome than cases with acute coronary syndrome and healthy subjects.

Principal conclusions: Joint link between psychological factors and broken heart syndrome emphasizes on behavioral therapies and psychological treatments for healing this entity.
\end{abstract}

Keywords: Personality Characteristics; Broken Heart Syndrome; Acute Coronary Syndrome.

\author{
*Corresponding Author: \\ Morteza Abdar-Esfahani, \\ Department of Cardiology, Faculty of Medicine, \\ Isfahan University of Medical Sciences, Isfahan, IR Iran. \\ Tel: +98-3112223369; Fax: +98-3116691482 \\ E-mail: abdariranian@yahoo.com
}

Received: March 15, 2014

Accepted: April 10, 2014

Published: April 12, 2014

Citation: Esfahani M A, Baluchi D, Behjati M, Izadi S (2014) Comparison of Personal Characteristic of Patients Affected By Broken Heart Syndrome and Acute Coronary Syndrome Vs. Healthy Subjects. Int J Behav Res Psychol. 2(3), 36-39. doi: http://dx.doi.org/10.19070/23323000-140007

Copyright: Esfahani $\mathbf{M ~ A}^{\circ}$ 2014. This is an open-access article distributed under the terms of the Creative Commons Attribution License, which permits unrestricted use, distribution and reproduction in any medium, provided the original author and source are credited.

\section{Introduction}

According to the bio-psychological model (biology- psychologysocial template), there is a joint link between psychological and somatic factors, in human being. Despite of the biologic heritage, personality factors lead to some somatic reactions [1]. There is a great emphasize on the relationship between somatic disorders and psychosocial disorders. Psychological stresses impose great burden on cardiovascular diseases as a leading cause of death, worldwide. Clinical investigations and observational studies imply the role of psychological factors on the development and progression of cardiovascular diseases [2]. Among these cardiovascular diseases, broken heart syndrome (BHS) is an entity that occurs due to dysfunction of myocardial performance by a severe physical or psychological stressgen factor [3]. Stress -induced cardiomyopathy is often but not always triggered by an intense emotional or psyshological stress (as domestic abuse, arguments, devasting financial losses, natural disasters, death of relatives and so on) and or acute medical illness [4 - 8].

There is a major difference between BHS and acute coronary syndrome [2]. Angiographic data from these patients demonstrate normal patent coronary arteries without any elevation in cardiac biomarkers. A rapid reversal to normal conditions (about 2 weeks) has been seen in these cases with complete recovery [9

-11]. But presence of chest pain and dyspnea mimics acute coronary events in emergency department [10]. It should be noted that in about one third of patients manifest with pulmonary congestion, arrhythmia and even elevated cardiac biomarkers [9]. These manifestations are often transient and brief. Cardiac biomarkers are much lower in these cases than patients with acute coronary events [9].

Anyway, personality characteristics are relatively stable but could change according to environmental factors [12]. Imbalance in personal characteristics progresses to the development of a syndrome and finally psychological disorders. It has been suggested that persons with certain psychological characters are susceptible 
to specific somatic disorders [13]. BHS is not considered as acute coronary syndrome and differs principally from conversion disorder[14]. BHS with prevalence of about $2 \%$ is a psycho-somatic disorder with physiological manifestations of an unwanted emotional condition [15]. $80 \%$ of these cases are women with mean range of 60 years old [16]. The key feature of BHS is occurrence of an acute physical or psychological stressgen event [17]. The diagnosis should be suspected in postmenopausal women presenting with acute coronary symdrome after intense psychological stress and ECG changes out of proportion to the degree of cardiac biomarker elevation[10]. Although, the majority of these symptoms subsides or vanishes after 3 weeks, but applying supportive cares could be used to accelerate therapeutic process [16]. Indeed, administration of medicines as angiotensin-converting enzymes (ACEI) and beta blockers till disappearance of symptoms is valuable.

The relationship between personal characteristics and BHS and its occurrence in persons older than 45 years old and post-menopausal women seek paying more attentions to the diagnosis of this syndrome to avoid diagnostic mistakes [18]. Since presence of underlying special psychological characters predispose persons to development of this syndrome, we aimed to find out predisposing personal characteristics and their difference between cases with BHS, acute coronary syndromes and healthy subjects.

\section{Materials and Methods}

Among 2000 cases with stress induced chest pain, patients with negative mild increased cardiac biomarkers, but normal coronary angiography and non-specific electrocardiographic changes, 60 cases were enrolled randomly in the group of BHS [19]. Indeed, among 3000 cases with chest pain, 60 patients with physician diagnosis of acute coronary syndrome were enrolled in the group of acute coronary syndrome. Third group, were 1000 healthy subjects (according to WHO criteria) without signs and symptoms of
BHS and acute coronary syndrome after matching with patients regarding demographic characteristics (age, gender, inhabitant, education and occupation). Sample volume of whole participants was evaluated to be 180 cases. Thus, in each group 60 cases were selected using simple random sampling based on the similarity in demographic characters. All participants enrolled in this investigation after getting signed informed consent.

SCL-90-R questionnaire: This 90-item quality was designed by Frank et al and measures depression, anxiety, paranoia, obsession, psychosis, stress in personal relationships, aggressiveness and hypochondriasis. Validity and reliability of this questionnaire was confirmed in Iranian population which showed high validity and reliability [20]. Investigator based modified SCL-90-R was constructed with 7 included questions. Kuder Richardson coefficient was used to evaluate its validity. In order to achieve consistency between data, derived scores from two tests with one month interval between them, on pilot cases were calculated and showed to be $66 \%$. Filled questionnaire were gathered and data were analyzed using SPSS ver.12 through MANOVA test.

\section{Results}

Demographic data of all cases are included in table-1. Gathered data from filled questionnaires are included in table- 2 as mean \pm SD. Phobia and paranoia parameters were highest and lowest in BHS groups, respectively. Indeed, in cases with acute coronary syndrome, anxiety and psychosis parameters were highest and lowest, respectively. In order to match SD in three groups for items of questionnaire, Levin test was used. As depicted in Table-3, the pre-test probability of equalization of SD for all items of questionnaire is confirmed $(\mathrm{P}<0.05)$. In table-4, MANOVA test was used to compare items of questionnaires after adjustment for confounders. Our data demonstrate that there is no significant inter group difference regarding depression, paranoia, obsession, hypochondriasis and inter-personal relationship $(\mathrm{P}>0.05)$.

Table 1: Frequency distribution of cases and their demographic data

\begin{tabular}{|c|c|c|c|c|c|}
\hline \multirow[t]{2}{*}{ Groups } & \multicolumn{4}{|c|}{ Gender } & \multirow[t]{2}{*}{ Total } \\
\hline & Single & Married & Single & Married & \\
\hline BHS & 10 & 36 & 4 & 10 & 60 \\
\hline CAD & 10 & 16 & 18 & 26 & 60 \\
\hline Healthy & 18 & 24 & 11 & 17 & 60 \\
\hline Total & 38 & 76 & 33 & 43 & 180 \\
\hline
\end{tabular}

Table 2: Descriptive statistics of Scl-90-R

\begin{tabular}{|l|l|l|l|l|l|l|l|l|l|l|}
\hline \multicolumn{2}{|c|}{ Groups } & Depression & Hypochondriasis & Psychosis & Anxiety & Obsession & Sensitivity & Phobia & Aggression & Paranoia \\
\hline \multirow{2}{*}{ BHS } & Mean & 1.46 & 1.35 & 1.38 & 1.44 & 1.42 & 1.32 & 1.48 & 1.31 & 1.29 \\
\cline { 2 - 12 } & SD & 0.97 & 0.86 & 1.1 & 0.99 & 0.98 & 0.92 & 1.01 & 1.02 & 0.94 \\
\hline \multirow{2}{*}{ CAD } & Mean & 1.2 & 1.24 & 0.91 & 1.27 & 1.07 & 1.05 & 1.05 & 0.95 & 1.11 \\
\cline { 2 - 12 } & SD & 0.9 & 0.83 & 1.01 & 0.91 & 0.9 & 0.94 & 0.94 & 0.07 & 0.95 \\
\hline \multirow{2}{*}{ Healthy } & Mean & 1.17 & 1.17 & 0.87 & 1.27 & 1.14 & 0.95 & 0.91 & 0.83 & 0.95 \\
\cline { 2 - 11 } & SD & 0.95 & 0.89 & 0.85 & 0.98 & 0.85 & 0.85 & 0.84 & 0.79 & 0.78 \\
\hline
\end{tabular}


Table 3: Levin test for equation of Sc190 scales

\begin{tabular}{|l|c|c|c|c|}
\hline Variables & $\mathbf{F}$ & $\mathbf{d F} 1$ & $\mathbf{d F 2}$ & $\mathbf{P}$ \\
\hline Depression & 0.9 & 2 & 177 & 0.4 \\
\hline Hypochondriasis & 0.36 & 2 & 177 & 0.69 \\
\hline Psychosis & 1.69 & 2 & 177 & 0.07 \\
\hline Anxiety & 0.79 & 2 & 177 & 0.45 \\
\hline Obsession & 1.46 & 2 & 177 & 0.23 \\
\hline Sensitivity & 1.76 & 2 & 177 & 0.17 \\
\hline Phobia & 1.98 & 2 & 177 & 0.14 \\
\hline Aggression & 1.52 & 2 & 177 & 0.11 \\
\hline Paranoia & 1.08 & 2 & 177 & 0.09 \\
\hline
\end{tabular}

Table 4: Manova test for Scle-90-r scales in groups

\begin{tabular}{|l|c|c|c|c|}
\hline Variables & MS & dF1 & F & P \\
\hline Depression & 1.52 & 2 & 1.712 & 0.18 \\
\hline Hypochondriasis & 0.44 & 2 & 0.654 & 0.52 \\
\hline Psychosis & 4.94 & 2 & 4.988 & 0.00 \\
\hline Anxiety & 0.56 & 2 & 0.598 & 0.55 \\
\hline Obsession & 2.00 & 2 & 2.369 & 0.09 \\
\hline Sensitivity & 2.23 & 2 & 2.671 & 0.07 \\
\hline Phobia & 3.44 & 2 & 3.916 & 0.02 \\
\hline Aggression & 3.82 & 2 & 4.259 & 0.01 \\
\hline Paranoia & 2.71 & 2 & 2.11 & 0.12 \\
\hline
\end{tabular}

Table 5: Comparison of mean values of variables between groups

\begin{tabular}{|l|l|l|l|l|l|}
\hline Variables & & Groups & Mean & SE & P \\
\hline Psychosis & BHS & 1.38 & 0.47 & 0.18 & 0.01 \\
\hline & CAD & 0.91 & 0.51 & 0.18 & 0.005 \\
\hline & Healthy & 0.86 & 0.04 & 0.18 & 0.8 \\
\hline Phobia & BHS & 1.48 & 0.33 & 0.17 & 0.05 \\
\hline & CAD & 1.05 & 0.46 & 0.17 & 0.007 \\
\hline & & 0.91 & 0.13 & 0.17 & 0.43 \\
\hline Aggression & BHS & 1.31 & 0.36 & 0.17 & 0.006 \\
\hline & CAD & 0.95 & 0.12 & 0.17 & 0.48 \\
\hline & & 0.83 & 0.12 & 0.17 & 0.48 \\
\hline
\end{tabular}

But psychosis $(\mathrm{P}<0.01)$ and aggressiveness/phobia parameters $(\mathrm{P}<0.05)$ showed to have significant difference between groups. Table-5 depicts the mean value of psychosis, aggressiveness and phobia between groups according to comparison of means. Our data demonstrate that mean values of psychosis, phobia and aggressiveness are higher in BHS cases than others $(\mathrm{P}<0.01)$. But values of this parameter showed no significant difference between acute coronary syndrome cases and healthy subjects $(\mathrm{P}>0.05)$.

\section{Discussion}

The main finding of our survey is higher prevalence of phobia and aggressiveness among patients with BHS compared with acute coronary syndrome and healthy subjects. Other parameters as depression, hypochondriasis, anxiety, obsession, paranoia and inter-personal stress showed non-significant difference between groups. Indeed, no difference was seen between cases with acute coronary syndrome and healthy subjects regarding phobia, psychosis and aggressiveness. Therefore, it could be concluded that psychosis, phobia and aggressiveness are associated with BHS. Denolt et al noted that aggressiveness and phobia could predispose persons to BHS, while Prasad et al and Sharkey et al relates fears and phobia to susceptibility for BHS, which is compatible with our findings [21-23]. Anyway, our data emphasize on the role of psychological parameters on development of BHS. Cases with BHS are in unhealthier state regarding psychosis, phobia and aggressiveness compared with other people even cases with acute coronary syndrome. Interestingly, in our survey there was no difference between cases with acute coronary syndrome and healthy subjects regarding personal characters which is controversial find- ing with previous reports. Compare A et al have considered type $\mathrm{D}$ personality as a risk factor for development of stress induced cardiomyopathy [24]. Atkinson et al (1985) and Friedman and Rosenman (1979) showed interaction between personal characteristics and acute coronary syndrome [25-26]. Thus, it could be concluded that in the present situation of our society, personal characteristics might no longer predict development of acute coronary syndrome, but it could be expected that with increased rate of aggressiveness, psychosis and phobia the prevalence of psychosomatic disorders as BHS would be increased. Thus, cases affected with BHS should be aware about this interaction. In this case, public education and informative workshops should be established. The role of psychologists in emergency departments should be more prominent. Indeed, an update overview on the relationship between type A personality character and acute coronary syndrome should be performed.

\section{Conclusions}

Joint link between psychological factors and broken heart syndrome emphasizes on behavioral therapies and psychological treatments for healing this entity.

\section{References}

[1] Mayer RG, Salmon P. Abnormal psychology. Masachosetts. Allyn and Bocon Inc 1988; 424-439.

[2] Sarason G, Sarason BR. Abnormal Psychology: The Problem of Maladaptive Behavior. Prentice-Hall Date Published: 1987.

[3] Wittstein IS, Thiemann DR, Lima JA, Baughman KL, Schulman SP, Gerstenblith G, Wu KC, Rade JJ, Bivalacqua TJ, Champion HC. Neurohu- 
moral features of myocardial stunning due to sudden emotional stress. $\mathrm{N}$ Engl J Med. 2005 Feb 10;352(6):539-48.

[4] Tsuchihashi K, Ueshima K, Uchida T, et al. Transient left ventricular apical ballooning without coronary artery stenosis: a novel heart syndrome mimicking acute myocardial infarction. Angina Pectoris-Myocardial Infarction Investigations in Japan. J Am Coll Cardiol 2001; 38:11

[5] Abe Y, Kondo M, Matsuoka R, et al. Assessment of clinical features in transient left ventricular apical ballooning. J Am Coll Cardiol 2003; 41:737

[6] Sharkey SW, Lesser JR, Zenovich AG, et al. Acute and reversible cardiomyopathy provoked by stress in women from the United States. Circulation 2005; 111:472

[7] Bybee KA, Prasad A, Barsness GW, et al. Clinical characteristics and thrombolysis in myocardial infarction frame counts in women with transient left ventricular apical ballooning syndrome. Am J Cardiol 2004; 94:343

[8] Watanabe H, Kodama M, Okura Y, et al. Impact of earthquakes on Takotsubo cardiomyopathy. JAMA 2005; 294:305

[9] Wittstein IS. "The broken heart syndrome." Cleve Clin J Med. 2007 Feb;74 Suppl 1:S17-22.

[10] Stress-induced (takotsubo) cardiomyopathy. Guy S Reeder, MD. www.uptodate.com. 1, 2008

[11] Sharkey S, Lesser J, Zenovich A. reversible cardiomyopathy provoked by stress in woman from united states. Washington: circulation 2005.

[12] Schultz DP, Schultz SE. Theories of Personality. Hardcover Publisher: Thomson Brooks.2001

[13] Kubasa Ch, Fernandes D, Clerck F. The economy and social pathology. England. London: Cambridge 1979.

[14] Davison G, Neale J. Abnormal Psychology. (Eighth ed), California: John Wiley \& Sons, Inc 2000.

[15] Park JH, Kang SJ, Song JK, Kim HK, Lim CM, Kang DH, Koh Y. Left ventricular apical ballooning due to severe physical stress in patients admitted to the medical ICU. Chest. 2005 Jul;128(1):296-302.

[16] Gianni M, Dentali F, Grandi A, Hiralal R, Ionn E. Appical ballooning syndrome or takotsubo cardiomyopathy. Eur Heart J. 2006 Jul;27(13):1523-9.

[17] Tsuchihashi K, Ueshima K, Uchida T, Oh-mura N, Kimura K, Owa M, Yoshiyama M, Miyazaki S, Haze K, Ogawa H, Honda T, Hase M, Kai R, Morii I; Angina Pectoris-Myocardial Infarction Investigations in Japan.
Transient left ventricular apical ballooning without coronary artery stenosis: a novel heart syndrome mimicking acute myocardial infarction. Angina Pectoris-Myocardial Infarction Investigations in Japan. J Am Coll Cardiol 2001;38(1):11-8.

[18] Alasti M, Mehrabanfar A, Adel M, Assareh A. Apical Ballooning Syndrome or Taku â “ Tsubo cardiomyopathy: what we know about it. The journal of Tehran University Heart Center 2007.

[19] Park JH, Kang SJ, Song JK, Kim HK, Lim CM, Kang DH, Koh Y. Left ventricular apical ballooning due to severe physical stress in patients admitted to the medical ICU. Chest 2005; 128(1):296-302.

[20] Kamkar M. The effect of successful Hemophilia Educational Plans on The Amount of Young Hemophilia Patients Anxiety in Isfahan Province. [Thesise for MSc]. Azad university 1379.

[21] Denolt J, Kupper N. Cortisol dysregulation as mediating mechanism. J Psychosom Res 2007;62(4).

[22] Prasad, A.; Lerman, A. \& Rihal, C. S. (2008). Apical ballooning syndrome (Tako-Tsubo or stress cardiomyopathy): a mimic of acute myocardial infarction. American Heart Journal, vol.155, No.3, pp. 408-417, ISSN 0002-8703

[23] Sharkey, S. W.; Windenburg, D. C.; Lesser, J. R.; Maron, M. S.; Hause, R. G.; Lesser, J. N.; Haas, T. S.; Hodges, J. S. \& Maron, B. J. (2010). Natural history and expansive clinical profile of stress (Tako-tsubo) cardiomyopathy. Journal of the American College of Cardiology, Vol.26, No.4, pp. 333-341, ISSN 0735-1097

[24] Compare A, Bigi R, Orrego PS, Proietti R, Grossi E, Steptoe A. Type D personality is associated with the development of stress cardiomyopathy following emotional triggers. Ann Behav Med. 2013 Jun;45(3):299-307. doi: 10.1007/s12160-013-9474-x.

[25] Atkinson RL, Atkinson RC, Smith EE, Bem DJ, Nolen-Hoeksema S, Hilgardâ $€^{\mathrm{TM}} \mathrm{s}$ introduction to psychology (13th edition). New York: Harcourt Brace Jovanovich 2000.

[26] Friedman Sh, Rosenman P. Different clues of personalities. (4th ed). Massachosette: Press 1979. 